\title{
Thought about Enchanting Enterprises' Technological Innovation Cost Management
}

\author{
Dashan Wang \\ Hainan College of Software Technology, Qionghai Hainan, 571400, China
}

Keywords: Enterprise, Technological innovation, Cost management

\begin{abstract}
Technological innovation and management innovation supplement each other. Once technological innovation process becomes complex, the demand for management reform will become increasingly urgent. This is a new requirement for productive relations due to continuous development of productivity. For enterprises, they must achieve synchronous development of technological innovation and management reform. This paper analyzes the implication and case of enterprises' technological innovation cost management, sets forth the necessity of enhancing enterprises' cost management of technological innovation and proposes countermeasures to further improve enterprises' technological innovation cost management of.
\end{abstract}

\section{Introduction}

Promotion of economic management benefit is an eternally important theme in business operation and development, while cost control is an important means for enterprises to intensify internal operation management and boost economic benefit. Meanwhile, it is also the key point of strengthening enterprise competitiveness. Hence, enterprises must further improve cost management level on the basis of ensuing safety and quality and control the cost within certain range. This is one of significant contents of enterprises' technological innovation management.

\section{Implication and case of enterprises' technological innovation cost management}

The academic circle has different views on enterprises' technological innovation cost management. Cost management is a general term of various scientific management behaviors for all kinds of cost conducted by enterprises in production and operation process. Usually, cost management covers cost forecast, cost decision making, cost accounting, cost control and cost assessment etc. The author considers that technological innovation cost management can be defined as enterprises' organized and systematic planning, decision, analysis, assessment and control of various expenses generated in technological innovation. The purpose of cost management is to make sure the value of new products or new processes can be achieved so as to realize innovation management objective, and reduce resource consumption as far as possible on the basis of improving enterprises' competitiveness.

The implementation of enterprises' technological innovation cost management can greatly boost business management level, offer strong support for technological innovation and enhance technological innovation achievement transformation. For example, Chang'an Auto actively researches and develops unmanned automobile technology and carries out technological innovation through cooperation with Chinese scientific research institutions, colleges and universities. Aiming at inelegance advantage of future automobile products, Chinese and foreign automobile enterprises accelerate the speed of research and development, and unmanned driving technology becomes an important research and development target. But, 1.3 billion Yuan may be required to improve the level of intelligent automobile technology such as unmanned driving. Thus, the enterprise is faced with capital shortage problem in technological innovation process.

\section{Necessary of enhancing enterprises' technological innovation cost management}

Firstly, it can well connect cost management and technological innovation management. In view of continuous research of the following two management methods, theoretical systems of the two 
keep relatively independent and lack intersection and combination. The researches on the former usually focus on subject subdivision, such as standard costing method, activity-based costing method and responsibility costing method. The researches on the letter become richer and richer due to continuous emergence of new information and new technology. Nowadays, enterprise management activity is becoming increasingly complex. How to effectively combine the two? The research on the interaction should be done to well connect theory and practice and drive faster and better development of technology enterprises in China.

Secondly, it can offer strong support for rational allocation of enterprises' technological innovation resources. In view of continuous rise in technological innovation investment, how to implement effective allocation of innovation resources has become an important content of cost control. Enterprises' resource input is limited, while cost management involves value increment and behavioral control. Cost management can be implemented through rationalizing cost control and management. Then, according to the particularity of technological innovation cost, all kinds of resources can be applied more rationally to avoid waste.

Thirdly, it can strengthen technological innovation achievement transformation. Enterprises' management ability will directly decide technological innovation effect. Once technological innovation cost increases, the profit can rise. Thus, enterprises need to rationally increase the cost of such activity so as to facilitate realization and transformation of innovation achievements. On the contrary, although the expenses of various activities in technological innovation have been controlled, profit level may continue to decline, and the loss caused by technological innovation will far exceed the decrease range of innovation cost. Thus, the cost of this activity should not be adjusted, but should facilitate technological innovation achievements through cost control in other aspects.

\section{Countermeasures to further improve enterprises' technological innovation cost management}

\section{To promote management of internal operation environment value chain}

It is required to formulate rational development strategy and tactics, and offer specific implementation plans. Enterprises should boost cost management efficiency. First of all, comprehensive analysis should internal operation environment of an enterprise must be done. A fundamental method is to analyze the value chain. It is required to conduct analysis based on industry value chain, practically know the position of an enterprise in the value chain. An enterprise can effectively know its value chain system based on analysis of internal management, and know the specific value chain of competitors through analyzing the competitors. In this way, the enterprise can know itself and the competitors and lay a favorable foundation for correctly formulating strategic cost management. Through environment analysis, each goal of the enterprise can keep consistency and consistency so that the enterprise can build rational goal network, while accurate goal contributes greatly to formulating, implementing and controlling the consistency. For instance, in order to further drive research and development of unmanned automobile product, Chang' an Automobile mentioned above should specify the next goal and formulate rational strategy, tactics and implementation scheme according to the conditions of automobile industry, internal and external enterprise environment as well as the goal. This is the primary step in enterprises' technological innovation cost management.

\section{To design the most reasonable cost management method based on enterprises' features}

Enterprises' cost management lays emphasis on rational control of product life cycle. The demand intensity for cost accounting of product life cycle is strong. Nowadays, the products of many enterprises are updated very fast. The life cycle is very short, and accounting is operable in practice. Enterprises' material consumption cost accounting and control is mostly from the perspective of value evaluation and value distribution. Besides, enterprise cost composition should be overall considered. In general, enterprises' manufacturing cost is very low, while the period cost is very high. Thus, the latest thought on cost management should be put forward by referring to the calculation method of product life cycle cost. Enterprises should take into account of the following contents in line with their features during confirming cost management: enterprises should give full play to their outstanding superiority in research and development. Enterprises' cost management is mostly 
reflected in specific behaviors, rather than improvement of equipment operation status and formation of strict management mechanism. Moreover, reasonable enterprise information linage channel should form to practically improve information transfer speed, intensify horizontal ties of each department, promote the ability to respond to customer demand, better apply the marketing platform to increase sales revenue and reduce the fixed cost of unit product. On this basis, enterprises should enhance early warning system construction. Early warning is divided into absolute early warning and relative warning. The red line of the former refers to specific expenditure capacity of cost decided by the breakeven point. The red line of the latter mainly includes longitudinal comparison red line and horizontal comparison red line. Longitudinal comparison red line is set by taking historical level value of company cost index as the basic standard, while horizontal comparison red line is set by regarding the level of competitors or industry level as the standard.

\section{To match independent innovation with cost differentiation strategy}

The former mainly refers to technological problem resolution by the enterprise's efforts and technological breakthrough. In this precondition, the enterprise depends on its practical ability to promote follow-up links of innovation, then achieves commercialization development of scientific and technological achievements and obtains corresponding market profits. Microsoft belongs to such enterprises. Under the guidance of independent innovation technology strategy, enterprises' cost management strategy should be positioned to the rise in research and envelopment input, pursuit of high-input and high-return cost control advantage and implementation of difference leadership development strategy. Once an enterprise can offer some unique and low-price products for buyers, this enterprise owns difference with other competitors. This strategy requires an enterprise to be far ahead or unique in this industry for the contents customers pay attention to, or it requires the enterprise to product more superior products with stronger functions and better services than competitors under the condition where cost gap cannot be further expanded so as to show operation difference. Naturally, this difference should be expected and accepted by buyers. Once an enterprise can really gain difference leadership position, it can naturally get premium reward beyond the price or sell more products at the corresponding price, or obtain extra profit such as customer loyalty in periodic and seasonal market shrinkage.

\section{To match imitative innovation with low cost strategy}

Imitative innovation mainly means enterprises learn and imitate innovative thinking and innovative behaviors of innovative enterprises so as to overall absorb successful experiences and lessons of leaders, introduce or decode unique core technology of leading enterprises, and improve the technology on this basis so as to further develop and innovate for development strategy. Under the guidance of this strategy, enterprises' cost management strategy must deeply mine their cost potential and implement cost leadership strategy. This is because imitative innovation technology strategy usually inputs on a large scale in the follow-up stages of process design, quality control, large-scale production and marketing innovation chain so as to produce new products with great competitiveness in performance, quality and price etc., overall compete against leading enterprises in this industry and lay an important position in industry. More importantly, the enterprise can gain corresponding economic benefit. For example, since Chang'an Automobile is confronted with insufficient technological level in unmanned driving technology innovation, it needs to import key components and carry out imitative innovation so as to really improve its technological level.

Correspondingly, enterprises should implement cost leadership strategy, i.e. win victory in competitions by depending on the cost and private lower than competitors. This is also an important strategy which can control absolute cost. Under active guidance of this strategy, the specific objective of an enterprise should become the low-cost service provider in the industry. In other words, the enterprise gains competition edge through cost control under the condition of making sure the functions and quality of products or services differ little. Once an enterprise can create and maintain overall cost leadership status, it can get the sale performance higher than the average level of the industry just through controlling the price at the average value of this industry or approaching this average value so as to transform cost leadership advantage to practical economic benefit. 


\section{Conclusion}

In conclusion, enterprises' technological innovation cost management lays many emphases on cost leadership and differentiation development strategy, which has great significance for technological innovation cost management. In terms of specific management mode, technological innovation can further drive product structure and manufacturing technique and control material loss from the source so as to more effectively control life cycle cost. Cost control will influence enterprises' technological innovation. Enterprises should control cost based on technological innovation, practically avoid inflation resulting from cost innovation and prevent innovation failure caused by investment limit excess. Thus, enterprise management level should carry out all-round and in-depth analysis of internal and external environment, make sure the products own difference feature and control cost within the range. It thus can be seen that enhancement of enterprises' technological innovation cost management cannot break away from cost control. Thus, it is necessary to practically increase the input in innovation cost under the view of technological innovation cost management so as to promote better development of enterprises.

\section{Acknowledgments}

This paper belongs to philosophy and social science project of Henan Province; project title: Study on Technological Innovation Cost of Innovative Enterprises in Henan Province (No.: 2012BFF036)

\section{References}

[1] Le Yanfen, Strategic Cost Management and Enterprise Competitive Advantage. Shanghai: Fudan University Press, 2006.

[2] Hu Hongwei, Research and Development Predicament. Beijing: Electronic Industry Press, 2009.

[3] Gao Yonggang, Cost Management Method of High-tech Enterprises. CFO, 2010 (12).

[4] Xie Yaping, Guo Baochun, Exploration and Analysis of New Modern Enterprise Cost Mode. Business Studies, 2005 (22).

[5] Wu Zhongxin, Zhang Rongwu, New Progress of Cost Management Theory and Its Influence on Enterprise Performance Evaluation. Systems Engineering, 2006 (2).

[6] Liu Binhong, Crisis ad Countermeasures of Cost Management of Private High-tech Enterprises. Reformation \& Strategy, 2004 (4). 